\title{
Public service motivation and ethical behavior: Evidence from three experiments
}

\section{Robert K. Christensen*, Bradley E. Wright ${ }^{\dagger}$}

\begin{abstract}
Public service motivation (PSM) research has grown rapidly in the last several decades, largely focused on the role of PSM in employment decisions and employee performance. More recently, researchers have raised the possibility that PSM may play a role in workplace ethical behavior. In this study we sought to empirically articulate this link with evidence from three experimental studies. Across three experiments our research fails to confirm the relationship between PSM and ethics. We measured ethics both attitudinally and observationally. We conclude that even if the null findings are due to sample characteristics or weaknesses in the priming intervention, the three studies reported here raise concerns regarding the ease with which one can influence behavior by "priming" PSM. PSM may increase ethical behavior but not always in ways that public managers and organizations can easily influence.
\end{abstract}

Keywords: Public service motivation, Ethics, Prosocial priming

$\mathrm{R}$ esearch on public service motivation (PSM) has grown considerably in the last twenty years (Ritz, Brewer, \& Neumann, 2016). PSM has been broadly defined as the desire or need that people have to contribute to society (Vandenabeele, Ritz, \& Neumann, 2018), and a great deal of research has focused on identifying and testing the extent to which PSM can explain and predict employee attitudes and behavior. Although much of this work has focused on its ability to predict employment decisions and employee performance (Wright, Hassan, \& Christensen, 2017), a growing number of studies have suggested that PSM can help explain if not increase ethical behavior in the workplace (Wright, Hassan, \& Park, 2016). Employees with higher PSM are expected to exhibit greater ethical behavior and decision-making because it is consistent with the underlying values and ideals that guide their identities. Both PSM and ethical behavior, for example, are defined in terms of

\footnotetext{
* Marriott School of Management, Brigham Young University

t School of Public and International Affairs, University of Georgia

Address correspondence to Robert K. Christensen at (rc@,byu.edu)

Copyright: (C) 2018. The authors license this article under the terms of the Creative Commons Attribution 4.0 International License.
}

advancing the public interest, helping others and addressing issues of social equity and individual rights. In addition to encouraging ethical behavior, PSM is also expected to reduce the attractiveness and likelihood of unethical behavior. While unethical behavior is typically driven by greed and selfinterest, employees with higher PSM not only put a higher priority on helping others but also place a lower value on their own self-interest and personal benefits (Wright et al., 2016).

Although past research has found that PSM increases ethical behavior and decision-making, these studies have relied on cross-sectional studies and self-reported ethical intentions (Wright, et al., 2016). As a result, these studies cannot make strong causal arguments for two reasons. First, such studies cannot fully control for alternative explanations of the differences between individuals with higher and lower PSM. Second, these studies fail to link PSM to actual ethical behavior. Building on the increased interest in the influence of PSM on ethical behavior (Wright et al., 2016) and recent work on strategies to enhance PSM (Bellé, 2013, 2014; Pedersen, 2015), this study will provide a stronger test of this relationship in two ways. First, by randomly assigning interventions intended to increase PSM, our study will be able to make stronger causal claims for PSM's effect on ethical decision- 
making and behavior. Second, our study will investigate PSM's effects on both ethical decision-making (i.e., the extent to which individuals claim that they would behave ethically) and ethical behavior (i.e., whether they actually do behave ethically). Thus, we test the following hypothesis:

\section{H1: PSM increases ethical decision-making and behavior.}

To test the hypothesized relationship between PSM and ethics, we conducted three experiments priming participants' PSM. While the first study tests PSM's relationship with ethical intentions (i.e., stated behavior), studies 2 and 3 test its relationship with ethical behavior (i.e., revealed behavior). To provide a strong test of the relationship between PSM and ethical behavior, we needed to randomly assign individuals to different levels of PSM. While we could not randomly assign public service values and motivation, we could randomly assign conditions under which an individual's PSM should be either enhanced or activated (Pedersen, 2014). Much of the research has focused on identifying and testing the extent to which PSM can explain and predict employee attitudes and behavior, but a growing number of studies have been investigating the ways to cultivate if not activate employee PSM. Some of these studies have focused on the role of leadership (Bellé, 2013, 2014; Wright et al., 2016; Wright, Moynihan, \& Pandey, 2012) and beneficiary contact (Bellé, 2013, 2014; Grant, 2008). Other studies have begun to apply lessons from the behavioral sciences to investigate the effectiveness of priming and self-persuasion, which are more conducive to experimental studies (Arieli, Grant, \& Sagiv, 2014; Bellé 2013, 2014; Linos, 2018; Pedersen, 2015). Although this research has been rather limited to date, researchers have found that self-persuasion can increase employee PSM (Bellé, 2013) and performance (Bellé, 2013, 2014). The effects of priming, however, are more mixed. While one recent study found that a simple PSM prime can increase the amount of time participants report to be willing to spend on a task (Pedersen, 2015), a second study did not find that a PSM prime increased the number of individuals that applied for a government job (Linos, 2018). In response to concerns about the efficacy and longevity of priming effects, studies have combined PSM priming and self-persuasion exercises to show not only an increase in benevolence values and self-reported willingness to volunteer but also that these primed effects on an individual's benevolence values can persist over time (Arieli et al., 2014). To maximize our potential to effectively manipulate PSM, in this study we followed the strategy of using an intervention that combines both priming and self-persuasion.

\section{Study 1}

\section{Participants and Design}

Data were collected from undergraduate students attending a large, private, and religiously affiliated university. The respondents were enrolled in courses where extra credit is offered by the instructor in exchange for lab/study participation. Through a Sona-based lab management platform, students-typically with a business minor or major-had the option to read about available studies, enroll, and then participate. We described this study as requiring 30 minutes or less (equals 1 credit of lab participation) and as taking place in a computer lab on campus. Participants were told that they would be asked to complete several exercises to help the research team study the relationship between personality and decision-making. Afterwards they would also be asked to complete a short questionnaire describing some basic demographic information including aspects of their personality and beliefs. The lab is located in the business college. Of the 226 participants that took part in the study, $62 \%$ were male and the average age was 21 years old. There were no statistically significant differences between the treatment and control group in gender or age.

The students were than randomly assigned to either a PSM prime or a control condition. Following the priming procedures developed by Arieli and colleagues (2014), participants completed four exercises designed to activate if not cultivate their PSM. ${ }^{1}$ First, the participants in the PSM priming condition were asked to read a short (420 words excluding citations) summary of the scientific evidence on how individuals are significantly more cooperative, compassionate, and helpful than most people realize and how that behavior can even be beneficial to the individual. Participants were then asked to identify the different ways in which acting with helpfulness and kindness play an important role in their own lives by completing a checklist of the ways in which they have helped others in the past month. In the third exercise, participants were asked to spend five minutes writing a story about 
how they (or someone they knew) made a significant difference in the lives of others. In the fourth and final exercise, participants were asked to take 10 minutes to write two persuasive paragraphs attempting to convince others that it is important to be benevolent, generous, and helpful. In the control condition, participants performed the same four exercises on the importance and frequency with which individuals are capable of changing their personality and abilities. A review of the treatment and control exercises suggested that the participants were engaged in their assigned tasks. ${ }^{2}$

\section{Measures}

To test whether the PSM priming treatment increased their ethical decision making, we used two previously established measures in which participants were presented with hypothetical situations and were asked how likely (from $0 \%$ to $100 \%$ ) they were to engage in the described (unethical) behavior. The first measure consisted of eight ethical scenarios commonly faced by college students (Detert, Treviño \& Sweitzer, 2008; Piff, Stancato, Côté, Mendoza-Denton, \& Keltner, 2012). The second measure consisted of a single scenario describing a hypothetical job negotiation and the likelihood that the study participant (representing the employer) would be honest with a job candidate regarding the pending elimination of the position offered due to organizational restructuring (for more details, see Aquino, Freeman, Reed, Lim, \& Felps, 2009; Piff et al., 2012).
After participants completed these measures of ethical decision-making, they were then asked to provide some basic demographic information-including age and gender. We used two measures to assess the extent to which the PSM prime enhanced their PSM. First, we used a commonly used five-item global measure of PSM (Wright, Christensen, \& Pandey, 2013). Second, we used a seven-item measure of the participants' attitude toward greed (Yamagishi \& Sato, 1986) given its strong link to unethical behavior (Bellé \& Cantarelli, 2017). For both measures, respondents indicated their agreement with each item on a sevenpoint scale (where strongly disagree $=1$ and strongly agree $=7)$.

\section{Results}

Means and standard deviations by condition appear in Table 1. No difference in the PSM or control priming conditions was found in the participant ethical decision-making $(p>.05)$ on either the eight ethical scenarios commonly faced by college students or the hypothetical job negotiation. In addition, no statistically significant difference was found between the treatment and control groups in either the five-item global measure of PSM or the seven-item measure of the participant's attitude toward greed $(p>.05)$. Together they not only suggest that the PSM prime did not increase ethical intentions but also that the prime's failure to do so may be due to its inability to prime or activate participant feelings of PSM.

Table 1

Experiment 1: Means by condition

\begin{tabular}{lccccc}
\hline \hline & \multicolumn{3}{c}{ Prime } & & \\
\cline { 2 - 3 } & PSM & Control & $t$ & df \\
\hline $\begin{array}{l}\text { Likelihood of Unethical Behavior } \\
\text { College Student Scenarios }\end{array}$ & 25.43 & 26.18 & & -.323 & 253 \\
& $(18.22)$ & $(18.93)$ & & \\
Job Negotiation Scenario & 70.85 & 70.08 & .212 & 254 \\
& $(28.51)$ & $(29.27)$ & & \\
Global PSM & 25.93 & 26.00 & -.131 & 254 \\
Greed & $(4.34)$ & $(4.16)$ & & \\
& 25.63 & 26.32 & 1.139 & 254 \\
\hline
\end{tabular}

Note: $*=p<0.05$. Standard Deviations appear in the parentheses below the means. 


\section{Study 2}

\section{Participants, Procedures, and Measures}

Undergraduate students were recruited in the same way and from the same university as study 1. Participants were randomly assigned to PSM and control treatment groups and completed the same exercises described in study 1 . Of the 225 participants that took part in the study, $60 \%$ were male and the average age was 22 years old. There were no statistically significant differences between the treatment and control group in gender or age. A review of the treatment and control exercises suggested that the participants were engaged in the assigned tasks. ${ }^{3}$

To test whether the PSM priming treatment increased ethical behavior, participants were asked to play a game of chance to determine if they would receive an additional incentive for completing the study. Adapting procedures developed by previous research (Piff et al., 2012), the computer presented them with a six-sided die to roll three times. They were asked to report their roll total and informed them that the higher their total score, the more entries they would receive into a prize drawing for a $\$ 100$ gift card. Although the first roll of the die was random, the last two rolls were manipulated to make sure that the total of the three rolls would equal 10 for each participant. Any participant reporting a score above 10 was considered to be cheating. As with study 1, after completing the ethical behavior measure, we also asked each participant to provide some basic demographic information (including age and gender) as well as complete a five-item global measure of PSM (Wright et al., 2013) and a seven-item measure of the participant's attitude toward greed (Yamagishi \& Sato, 1986).
Results

Very few students cheated (four in the PSM treatment condition and only 1 in the control condition). A two-sample t-test indicated that individuals in the PSM prime group were no less likely to cheat by reporting inflated scores on the dice roll exercise than those exposed to the control prime $(t(253)=$ $1.373, p>.05)$. In addition, no difference $(p>.05)$ was found between the treatment and control group in either the global measure of PSM or the measure of the participant's attitude toward greed (Table 2). As with study 1, study 2 found no evidence that the PSM prime activated or increases participant PSM or ethical behavior.

\section{Study 3}

\section{Participants, Procedures, and Measures}

Undergraduate students were recruited in the same way and from the same university as studies 1 and 2. Unlike the previous studies, however, the experiment was conducted online rather than in a lab. Participants were randomly assigned to PSM and control treatment groups and completed the same exercises described in studies 1 and 2. Of the 446 participants that took part in the study, $58 \%$ were male and the average age was 22 years old. There was no statistically significant difference between the treatment and control group in gender or age. A review of the treatment and control exercises suggested that the participants were engaged in the assigned tasks. ${ }^{4}$

To test whether the PSM priming treatment increased their ethical behavior, participants were asked to play a game of chance to determine if they would receive an additional incentive for completing the study. Similar to study 2 , the computer presented participants with a six-sided die to

Table 2

Experiment 2: Means by condition

\begin{tabular}{|c|c|c|c|c|}
\hline & \multicolumn{2}{|c|}{ Prime } & \multirow[b]{2}{*}{$t$} & \multirow[b]{2}{*}{$\mathrm{df}$} \\
\hline & PSM & Control & & \\
\hline Global PSM & $\begin{array}{l}26.58 \\
(4.31)\end{array}$ & $\begin{array}{l}26.36 \\
(4.51)\end{array}$ & 403 & 254 \\
\hline Greed & $\begin{array}{l}26.66 \\
(4.41)\end{array}$ & $\begin{array}{l}26.99 \\
(4.75)\end{array}$ & -.588 & 254 \\
\hline
\end{tabular}

Note: $*=p<0.05$. Standard Deviations appear in the parentheses below the means. 
roll three times and they were asked to report their roll total. As the die rolls were predetermined to sum up to 10 , any participant reporting a score above 10 was considered to be cheating. Given that there were very few cheaters in study 2 , we took two additional steps to strengthen the study. First, we increased the sample size and hence statistical power. Second, we tried to increase the likelihood of cheating by telling participants that the dice game would directly determine their additional reward instead of increasing the likelihood that they would be rewarded (more entries in a drawing). Participants were informed that the die roll total would be used to determine the number of lab credits they received for participating in the study (those with dice score totals of 3-10 would receive 1 additional lab credit, 11-14 would receive 2 additional credits and 15-18 would receive 3 additional credits). The latter two options raise the possibility of doubling or tripling the amount of extra credit a student can receive.

As with studies 1 and 2, after completing the ethical behavior measure, participants were asked to provide some basic demographic information and complete the five-item global measure of PSM (Wright et al., 2013) and the seven-item measure of the participant's attitude toward greed (Yamagishi \& Sato, 1986).

\section{Results}

As expected, the increased sample size and changes in the incentives for cheating increased the number of students that cheated. Even so, very few students $(n=18)$ cheated and the cheating was equally distributed across each group. A two-sample t-test indicated that individuals in the PSM prime group were no less likely to cheat by reporting inflated scores on the dice roll exercise than those exposed to the control prime $(t(447)=-0.10, p>.05)$. Unlike studies 1 and 2, however, study 3 found evidence (Table 3) that the PSM prime did enhance or activate prosocial values. An independent-samples ttest indicated that individuals in the PSM prime group reported higher levels of PSM $(M=27.30$, $S D=4.05)$ than the control group $(M=25.90, S D$ $=4.25), t(444)=3.546, p<.05$. An independentsamples t-test also indicated that individuals in the PSM prime group reported lower levels of greed $(M$ $=26.24, S D=4.11)$ than the control group $(M=$ $27.54, S D=4.39), t(445)=-3.283, p<.005$. Although these differences were statistically significant, the effects sizes were relatively small $(d=$ 0.336 and -0.311 , respectively). While the PSM prime increased participant PSM, the higher levels of PSM did not alter ethical behavior.

\section{Discussion and Conclusion}

Our research fails to confirm the relationship between PSM and ethical behavior found by previous studies (e.g., Wright et al., 2016). This conclusion is consistent across three experiments and holds true when looking at PSM's relationship with both ethical decision-making (extent to which individuals claim that they would behave ethically) and ethical behavior (whether they actually do behave ethically). One potential explanation for these findings is that there is no consistent relationship between PSM and ethical behavior. Past empirical support for the relationship may be explained by conditions specific to the situations studied or as artifacts of the methods used. Across our studies, the relationship disappears in the context of a randomized controlled research design.

Regardless of the care taken in designing and implementing the research design, we must be

Table 3

Experiment 3: Means by condition

\begin{tabular}{lcccc}
\hline \hline & \multicolumn{3}{c}{ Prime } & \\
\cline { 2 - 3 } & PSM & Control & $t$ & df \\
\hline Global PSM & 27.30 & 25.90 & $3.546^{*}$ & 444 \\
& $(4.05)$ & $(4.25)$ & & \\
Greed & 26.24 & 27.54 & $-3.283^{*}$ & 445 \\
& $(4.11)$ & $(4.39)$ & & \\
\hline
\end{tabular}

Note: $*=p<0.05$. Standard Deviations appear in the parentheses below the means. 
cautious in making strong claims from our findings. The study's inability to confirm the expected relationship between PSM and ethical behavior may be explained by alternative and equally plausible explanations. It is possible, for example, that not enough was done to incentivize cheating. Although previous studies have used these same ethical decisionmaking and behavioral measures to successfully find differences in other populations (Aquino et al., 2009; Detert et al., 2008; Piff et al., 2012), more may have been needed to incentivize cheating in the student population studied here. Given that the participants were students at a religiously affiliated university, they may already be especially unlikely to behave unethically for strongly felt religious reasons. There are reasons, however, to discount this explanation. First, while our samples do seem less likely to behave unethically than some previous studies using the same measures, the ethical decision-making scales suggest a fair amount of variation exists. ${ }^{5}$ Second, the relationship between religion and ethical behavior is often not as strong as expected with some scholars concluding that they "are left to ponder why religion does not have a significant impact in reducing cheating behavior (Hood, Spilka, Hunsberger, \& Gorsuch, 1996, p. 371). Research looking specifically at the relationship between religion and ethical behavior of college students suggests that the relationship is not very strong or consistent. While some studies have found no differences in ethical behavior between religious and nonreligious students (Smith, Wheeler, \& Diener, 1975), others have found that student religiosity can have statistically significant but small effects (Bloodgood, Turnley \& Mudrack, 2008), or that students at private religious colleges only respond more ethically than students at secular colleges on less than $30 \%$ of ethical scenarios (Conroy \& Emerson, 2004). Finally, given that the prevalence of cheating may be lower in the study population, steps were taken to increase the incentive to cheat by increasing the amount (study 2 ) or likelihood (study 3) of cheating, as well as the using larger sample sizes to increase the ability of the study to find differences between the groups. Even taking all of this into account, it is possible that a stronger incentive or different study population could produce different results.

A second potential explanation for these findings is that the intervention used was ineffective to prime the PSM of study participants. PSM primes can influence behavior through cultivating (increasing) an individual's PSM or by activating (encouraging the individual to act on) their existing level of PSM (Pedersen, 2015). Although there is no evidence that PSM activation occurred, this may be because the prime did not activate PSM or that it was activated but had little influence on ethical behavior or decision-making. ${ }^{6}$ There is some evidence, however, that the PSM prime can cultivate the PSM of participants, as PSM was found higher in one group that received the PSM prime. Unfortunately, this effect was only found in one of the three studies and may highlight the difficulty of cultivating an individual's PSM. It is also possible that PSM was difficult to prime because the study population (students at a religiously affiliated university) may already have such high levels of PSM that increasing it would be difficult. To the extent that this is a problem, however, we would also expect that it would be difficult to prime PSM in public employees, and yet PSM has been successfully primed in public employees with higher PSM levels than reported in our student sample. ${ }^{7}$ To limit the likelihood that these results could be due to a failure of the PSM priming intervention, we used a stronger intervention-combining both priming and self-persuasion - that had been shown to have a positive effect on PSM-related values and behaviors in multiple studies (Arieli et al., 2014). Nevertheless, it is possible that such interventions would be more effective when the priming highlights the link between PSM and specific work outcomes instead of the generic priming and self-persuasion activities used in this study. While some studies have shown that such generic activities can enhance public service behavior and values (Arieli et al., 2014), other studies have utilized self-persuasion exercises that are more directly tied to specific work settings (Bellé, 2013, 2014) or public service outcomes (Pedersen, 2015).

In conclusion, contrary to expectations, this study did not find support for claims that PSM increases ethical decision-making or behavior. The findings of any one set of studies, however, may be due to chance, weaknesses in how the variables were operationalized, or characteristics of the study sample or conditions. Future research needs to investigate this relationship using different samples, PSM primes, and measures of ethical behavior. Even if the failure to find a relationship is due to the sample characteristics or weaknesses in the priming intervention, the studies reported here do raise concerns regarding the ease with which one 
can influence behavior by activating or cultivating PSM. PSM may increase ethical behavior but not always in ways that public managers and organizations can easily influence. As previously noted, priming exercises are sometimes (Areili et al., 2014; Bellé, 2013, 2014; Pedersen, 2015) but not always effective (Linos, 2018). Future research needs to investigate the effectiveness of such strategies, including the conditions under which they are more likely to have the desired effect on individuals' public service behavior and values.

\section{Acknowledgement}

This research is supported by National Research Foundation of Korea (NRF-2014S1A3A2044898).

\section{Notes}

1. Although Areili et al. (2014) did not test whether the prime increased PSM as measured here, they did find that the prime increases benevolence values (a four-item scale that included an item asking about their desire to work for the welfare of others) and signing up for community volunteer work. The extent to which an individual values service to or helping others (Wright et al., 2013) and volunteering (Houston, 2006) have often been used to measure PSM.

2. Participants in both the treatment and control groups wrote at length and on topic for each exercise. In exercise 3, those in the PSM treatment wrote 152 words on average while those in the control treatments averaged 147 words. In exercise 4, those in the PSM treatment wrote 199 words on average while those in the control treatments averaged 206 words.

3. As with study 1, participants in both the treatment and control groups wrote at length and on topic for each exercise. In exercise 3, those in the PSM treatment wrote 144 words on average while those in the control treatments averaged 148 words. In exercise 4, those in the PSM treatment wrote 203 words on average while those in the control treatments averaged 212 words.

4. As with the previous two studies, participants in both the treatment and control groups wrote at length and on topic for each exercise. In exercise 3, those in the PSM treatment wrote 134 words on average while those in the control treatments averaged 123 words. In exercise 4, those in the PSM treatment wrote 150 words on average while those in the control treatments averaged 155 words.

5. While our students reported they were (on average) $70 \%$ likely to tell the truth in the job negotiation scenario in study 1 , an MTurk sample used in a previously published study reported only a $62 \%$ likelihood of telling the truth (Piff et al., 2012). No direct comparisons can be made with the eight-item college ethical scenario scale due to differences in response scales (although previous studies used a strongly agree-disagree Likert scale, our study used a percent likelihood scale), but nearly one-third $(29 \%)$ of our sample reported being most likely $(>50 \%)$ to engage in at least 3 of the 8 unethical actions.

6. One reviewer also raises the possibility that the Arieli et al. (2014) primes used in our study were designed to increase prosocial values and motivation and may not necessarily increase PSM. We recognize this as a possibility but find compelling the high empirical correlation between self-reported prosocial motivation and PSM (see Wright et al., 2013). Nevertheless, future studies might include the Arieli et al. (2014) measures as a valuable point of reference alongside PSM measures.

7. Bellé (2014) used the same five-item measure on a 7 -point but on a 0 to 6 scale and reported the mean (not total) score. After converting his data to the same scale (using 1 to 7 point response scale and reporting the five-item total instead of the mean), the PSM in his six study groups ranges from 27.45 to 28 while the PSM in the samples and treatment groups of this study ranged from 25.43 to 27.3 with a mean across groups of 26.3 . 


\section{References}

Aquino, K., Freeman, D., Reed, A., II, Lim, V. K., \& Felps, W. (2009). Testing a social-cognitive model of moral behavior: The interactive influence of situations and moral identity centrality. Journal of Personality and Social Psychology, 97(1), 123.

Arieli, S., Grant, A. M., \& Sagiv, L. (2014). Convincing yourself to care about others: An intervention for enhancing benevolence values. Journal of Personality, 82(1), 15-24.

Bellé, N., \& Cantarelli, P. (2017). What causes unethical behavior? A meta-analysis to set an agenda for public administration research. Public Administration Review, 77(3), 327-339.

Bellé, N. (2013). Experimental evidence on the relationship between public service motivation and job performance. Public Administration Review, 73(1), 143-153.

Bellé, N. (2014). Leading to make a difference: A field experiment on the performance effects of transformational leadership, perceived social impact, and public service motivation. Journal of Public Administration Research and Theory, 24(1), 109-136.

Bloodgood, J. M., Turnley, W. H., \& Mudrack, P. (2008). The influence of ethics instruction, religiosity, and intelligence on cheating behavior. Journal of Business Ethics, 82(3), 557-571.

Conroy, S. J., \& Emerson, T. L. (2004). Business ethics and religion: Religiosity as a predictor of ethical awareness among students. Journal of Business Ethics, 50(4), 383-396.

Detert, J. R., Treviño, L. K., \& Sweitzer, V. L. (2008). Moral disengagement in ethical decision making: A study of antecedents and outcomes. Journal of Applied Psychology, 93(2), 374.

Grant, A. M. (2008). Employees without a cause: The motivational effects of prosocial impact in public service. International Public Management Journal, 11(1), 48-66.

Hood, R. W., Jr., Spilka, B., Hunsberger, B., \& Gorsuch, R. (1996). The psychology of religion: An empirical approach. New York, NY: Guilford Press.

Houston, D. J. (2006). "Walking the walk" of public service motivation: Public employees and charitable gifts of time, blood, and money. Journal of Public Administration Research \& Theory, 16(1), 67-86.

Linos, E. (2018). More than public service: A field experiment on job advertisements and diversity in the police. Journal of Public Administration Research and Theory, 28(1), 67-85.

Pedersen, M. J. (2015). Activating the forces of public service motivation: Evidence from a low-intensity randomized survey experiment. Public Administration Review, 75(5), 734-746.

Piff, P. K., Stancato, D. M., Côté, S., Mendoza-Denton, R., \& Keltner, D. (2012). Higher social class predicts increased unethical behavior. Proceedings of the National Academy of Sciences, 109(11), 4086-4091.

Ritz, A., Brewer, G. A., \& Neumann, O. (2016). Public service motivation: A systematic literature review and outlook. Public Administration Review, 76(3), 414 426.

Smith, R. E., Wheeler, G., \& Diener, E. (1975). Faith without works: Jesus people, resistance to temptation, and altruism. Journal of Applied Social Psychology, 5(4), 320-330.

Vandenabeele, W., Ritz, A., \& Neumann, O. (2018). Public service motivation: State of the art and conceptual cleanup. In E. Ongaro \& S. Van Thiel (Eds.), The Palgrave Handbook of Public Administration and Management in Europe (pp. 261-278). London: Palgrave Macmillan.

Wright, B. E., Christensen, R. K., \& Pandey, S. K. (2013). Measuring public service motivation: Exploring the equivalence of existing global measures. International Public Management Journal, 16(2), 197-223.

Wright, B. E., Hassan, S., \& Christensen, R. K. (2017). Job choice and performance: Revisiting core assumptions about public service motivation. International Public Management Journal, 20(1), 108-131.

Wright, B. E., Hassan, S., \& Park, J. (2016). Does a public service ethic encourage ethical behaviour? Public service motivation, ethical leadership and the willingness to report ethical problems. Public Administration, 94(3), 647-663.

Wright, B. E., Moynihan, D. P., \& Pandey, S. K. (2012). Pulling the levers: Transformational leadership, public service motivation, and mission valence. Public Administration Review, 72(2), 206-215.

Yamagishi, T., \& Sato, K. (1986). Motivational bases of the public goods problem. Journal of Personality and Social Psychology, 50(1), 67. 